*Forthcoming in the Canadian Journal of Philosophy*

\title{
Mental imagery and fiction
}

\section{Dustin Stokes}

Department of Philosophy, University of Utah, Salt Lake City, U.S.A.

\author{
dustin.stokes@utah.edu
}

\begin{abstract}
Fictions evoke imagery, and their value consists partly in that achievement. This paper offers analysis of this neglected topic. Section I identifies relevant philosophical background. II offers a working definition of imagery. III identifies empirical work on visual imagery. IV and V criticize imagery essentialism, through the lens of genuine fictional narratives. This outcome, though, is not wholly critical. The expressed spirit of imagery essentialism is to encourage philosophers to "put the image back into the imagination." The weakened conclusion is that while an image is not essential to imagining, it should be returned to our theories of imagination.
\end{abstract}

Keywords: imagery; imagination; fiction; narrative; language processing; imagery essentialism 
Eating is unattractive too... Various items get gulped into my mouth, and after skillful massage with tongue and teeth I transfer them to the plate for additional sculpture with knife and fork and spoon. That bit's quite therapeutic at least, unless you're having soup or something, which can be a real sentence. Next you face the laborious business of cooling, of reassembly, of storage, before the return of these foodstuffs to the Superette, where, admittedly, I am promptly and generously reimbursed for my pains. Then you tool down the aisles, with trolley or basket, returning each can and packet to its rightful place.

M. Amis, Time's Arrow

When reading the above bit of narrative, many will form sensory images. But some readers may not be familiar with an important feature of Time's Arrow: the first person narrative proceeds, in time, backwards. With this in mind, one might read the passage a second time. Much of the charm (and terror) of Amis's novel is performing these rather difficult mental tasks: forming images of actions and events from the banal to the horrific, and imaging those actions and events proceeding in reverse, as it were, in time. Here Amis's prose operates like a puzzle. One unlocks the puzzle, if one wishes to appreciate the artistic achievement, by forming visual images of the main character's life run in reverse. Eating is a familiar activity for any reader, and so one way to understand and appreciate the first line of the passage is to mentally "picture" the ordinary course of events of eating, mentally reverse its temporal order, and thereby appreciate events from the amusing to the unpleasant.

The distinctive temporal structure notwithstanding, Amis's novel is not particularly special in the following regard. Fictions clearly evoke imagery, and their value-aesthetic, emotional, cognitive - consists partly in their successfully doing this. In short, imagery is an important feature 
of how we engage fictional narratives. ${ }^{1}$ Given the richness of philosophical research on imagination and fiction (and imagination and fiction) in the past few decades, one would reasonably expect ample discussion of imagery as it pertains to experiences of fiction. There is, however, a scarcity of philosophy of imagery and fiction.

One exception to this neglect is the imagery-based account of imagination given by Amy Kind. ${ }^{2}$ Kind defends the claim that images are essential to instances of imagining, which she qualifies: "imagery [is] necessary, but not sufficient to make a mental exercise an exercise of the imagination" (2001: 100). Kind's argument for this claim is that no non-imagery based theory of imagination will adequately explain all features of our activities of imagining. Kind's view is illuminating but her essentialist claim is, it will be argued here, false. This is most clearly revealed by analysis of cases that Kind herself does not seriously consider, namely, passages from genuine fictional narrative. The critical analysis of Kind's position nonetheless rescues lessons from her project. Philosophers of fiction specifically and of imagination more generally, should make imagery a central explanandum; they should, in a way that allies with Kind's central claim, put imagery back in their theories of imagination.

\section{Imagery, propositional imagination, and fiction}

Suppose you are asked to imagine Socrates drinking the hemlock. One way you might do this mentally is to, in folk terms, "picture" Socrates, perhaps holding a goblet, and surrounded by

\footnotetext{
1 The emphasis here is exclusively on written fictional narrative, with no discussion of pictures, photography, or film. And for that matter, much of this analysis could also apply to non-fictional works that evoke, or function to evoke, imagination. A related question concerns how one distinguishes fiction from non-fiction, and whether one thinks the distinction can be drawn along essentialist lines. Stacie Friend has argued that fiction and non-fiction should instead be understood as categories of genre "whose membership is determined by a cluster of non-essential criteria" (2012: 203; see also 2008. So while the explicit emphasis here will be on works standardly categorized as fictions, the reader should note that some works (standardly) categorized as non-fictions may also serve a role of evoking imagery. Thank you to an anonymous reviewer for making this suggestion.

2 Another of the few exceptions is Lopes (2003), which will be discussed below. See also Nanay (forthcoming B).
} 
his followers. This is to form a mental image or visualize, where the format of the representation is like both a pictorial representation and like a visual experience. ${ }^{3}$ But it also seems-or so some have claimed - that one might comply and successfully imagine the scenario, where the mental representation one forms does not take any distinctively pictorial or visual format, but instead just involves imagining that an event took place, that Socrates drank the hemlock. As it is often put, the first involves a pictorial or imagistic representational vehicle, the second a sentential representational vehicle (even if the representational content is the same). In recent decades, philosophical emphasis has shifted from imagistic models of imagination to a propositional model. A brief sketch of this history is in order.

Departing from Plato, who derided images as deceptive because far removed from his posited reality of the Forms, Aristotle characterizes imagination as important to various facets of cognition and understanding. Aristotle took imaginative states to be copies or internal pictorial representations of external objects, emphasizing the use of mental images in both memory and reasoning. ${ }^{4}$ That tradition extends to early modern theorizing. Descartes, Hume and Hobbes all made significant appeal to concepts of imagery in their philosophical theories. And indeed, the philosophy of John Locke makes images central. Locke's view, on one plausible interpretation, takes ideas, which are the building blocks of thought, to be mental images. And these mental images, according to the empiricist doctrine, ultimately derive from experience (1690/2004). This was no less true in early scientific psychology of the 19th and early 20th century, most especially in the work of figures like William James (1890), E.B. Titchener (1909), and Wilhelm Wundt (1912). These

\footnotetext{
${ }^{3}$ What these ways of resemblance are, more precisely, is discussed in II below.

${ }^{4}$ De Anima iii 3. See also Shields (2016).
} 
researchers placed emphasis both on the quasi-perceptual nature of imagination and theorized it as having a central role in cognition. ${ }^{5}$

The contemporary emphasis has moved away from imagery and instead to what has standardly become known as 'propositional imagination'. Two seminal works in this regard are Currie (1990) and Walton (1990), both of which give an analysis of the imagination and its role in our mental engagement with and appreciation of fictions. These works, and the decades of research that followed, characterize imagination, broadly, as a propositional attitude. To imagine Bolt winning the $100 \mathrm{~m}$ dash is, like believing or desiring, to token an attitude with the propositional content—that Bolt wins the $100 \mathrm{~m}$ dash. Thus one make-believes that P. ${ }^{6}$ In a similar vein, one (but not the only) dominant strand of research on the folk psychological capacity for mindreading, around that same time period, theorized mental simulation as the mechanism by which normal human subjects understand other minds via mental state attribution. What's simulated are the propositional attitudes of the target agent (whose actions one wants to explain or predict). Here again the imaginative activity takes a propositional form. ${ }^{7}$ Finally, concurrent work in modal epistemology explicitly favoured the propositional. Imagining that $\mathrm{P}$, on one common line of thought, is at least a good guide to knowing (or justifiably believing) that possibly P. Modal imagining was supposed not to require images, but instead consistency and coherence amongst the propositions that one imagines. ${ }^{8}$

\footnotetext{
${ }^{5}$ For informative discussion of this historical trajectory, and the philosophy and cognitive science of imagery generally, see Thomas (2016).

${ }^{6}$ This need not be a categorical point. As one anonymous reviewer points out, Walton (1990) does consider images. (It is worth emphasizing, however, that Walton's emphasis is on depiction in some perceptible medium, rather than sensory images, and he still theorizes this within the make-belief framework). And Currie and Ravenscroft (2002) do more explicitly analyze sensory imagery. The point here is nonetheless that the work of Walton and Currie set a research trajectory dominantly focused on propositional (non-imagistic) imagination.

${ }^{7}$ See Davies and Stones (1995, 1995b); Carruthers and Smith (1996); Nichols and Stich (2003). Other recent models of mindreading have placed emphasis on the simulation of action, motor planning, and emotion. See Jeannerod (1998, 2001); Gallese (2000); Rizzolatti and Sinigaglia (2008); Butterfill and Sinigaglia (2012).

${ }^{8}$ See Yablo (1993), Chalmers (2002). For a collection on the topic see Gendler and Hawthorne 2002. For a discussion of the relation between fiction and modal knowledge, see Stokes (2006)
} 
This trend - an emphasis on propositional imagination — marks a de-emphasis on the imagistic. Examples are abundant.

"When we engage in the sort of make-believe that contemplation of fictional scenarios evokes, we are largely unconstrained by what we take to be factual. We have no trouble imagining that Sherlock Holmes solved mysteries in nineteenth-century London, that an owl and a pussycat went out to sea in a beautiful pea-green boat, or that a hobbit named Frodo Baggins carried a magic ring all over Middle Earth" (Gendler 2000: 56-7; emphasis added).

"I will simply stipulate that at least some fictions ask us to imagine, with the added proviso that by 'imagining' I don't mean anything particularly full-blooded; for instance, it need not involve imagery nor even anything particularly experiential... That is, I will be concerned with what is sometimes called 'propositional' imagining..." (Stock 2013: 887)

"[...] attitude imaginings needn't have an imagistic representational format. When I imagine, on reading Lord of the Rings, that elves can live forever, I'm fictionally imagining a proposition that I couldn't imagine using mental imagery. It would take too long! So presumably I represent this in a more abstract symbolic code..." (Van Leeuwen 2013: 222).

Now of course there is nothing wrong with clearly identifying one's choice of explanandum, and these authors are partly doing just that. The point is simply that there is a dominant, pervasive emphasis on propositional imagination in contemporary philosophy, all the more dominant in theories of fiction, and it is often coupled with an explicit de-emphasis of mental imagery. ${ }^{9}$

\section{Mental imagery}

What kind of mental state or process is imagery? Perhaps imagery can be unconscious, but it is often experiential. ${ }^{10}$ Imagery experiences are conscious and enjoy phenomenological character. These are the mental phenomena central to imagery essentialism. Further, they are the kind of imagery of interest to philosophy of fiction. On a broad and standard account of aesthetic value, at

\footnotetext{
${ }^{9}$ One clear exception is the philosophy of perception literature, where imagery continues to receive attention. Many of these works are discussed and cited below. Additionally, see Tye (1991); Matthen (2005); Thompson (2008); Gregory (2010).

10 See Nanay (2010) and Pearson and Westbrook (2015) on the possibility of unconscious imagery.
} 
least part of what determines the value of a work of art is the experience that one can or should have with the work. Included amongst those experiences are imagery experiences, and a work of fiction might be valued for the conscious imagery it properly evokes in readers. The imagery of interest here, then, is conscious imagery experience (leaving open the possibility for unconscious imagery).

Acknowledgement of its experiential aspect points to a familiar observation about imagery: it is "quasi-perceptual". Imagery is like perception in one important way, but distinct from perception in two important ways. So, first, imagery is like perception in the sense that it is a conscious experience that represents objects and their features in a way that resembles the content and phenomenology of perceptual experience. Thus imagery experiences are typically in a specific sensory modality. ${ }^{11}$ Visual imagery represents visually perceptible properties—colours, shapes, motion, depth, and whatever else vision represents — and in a way that is bound into a whole object or scene or event. Accordingly, the first person phenomenology of a visual imagery experience resembles the first person phenomenology of an analogous visual perceptual experience. Subjectively, visually imagining a redwood tree resembles visually perceiving a redwood tree. Evidence that this resemblance is non-trivial comes from first person description: the descriptions one gives of one's visual image of the redwood will overlap substantially with the descriptions one gives of one's visual perception of the redwood. ${ }^{12}$

Imagery is unlike perception in the sense that it typically occurs in the absence of the relevant or appropriate cause(s). Except in rather unusual circumstances, if one is visually imagining a redwood tree, one is not (and certainly need not be) in the presence of an actual redwood tree. Imagery is not stimulus-driven in anything like the way perception is and this reveals part of its

\footnotetext{
11 This is not intended to rule out cross-modal or multi-modal imagery. See Stokes and Biggs (2014) for recent work on differences and interaction between sensory modalities. The primary emphasis here, though, is on visual imagery. ${ }^{12}$ Further evidence comes from the substantial empirical literature on imagery-perception interference effects, to be discussed in IV below.
} 
value: we can image objects, events, and features that are entirely absent from our current environmental surroundings.

For present interest, we could stop here: imagery experiences resemble_representationally and phenomenally_-perceptual experiences but, typically, in the absence of the appropriate external stimulus. However, there is cause to identify some third distinguishing feature of imagery. For all that has been said, imagery has been distinguished from (veridical) perceptual experience but not from perceptual illusion and hallucination. If one suffers a visual hallucination as of a redwood tree, it meets both specified conditions: one has an experience representationally and phenomenally similar to perceiving a redwood tree, but (at least typically) in the absence of an actual redwood tree. There are reasons to maintain that imagery is distinct from illusion and hallucination, even if it is similar in these two regards. One reason is cognitive-behavioural: all else being equal, if one has an illusory or hallucinatory experience as of some object $o$ being $F$, one will judge that $o$ is $F$ and perhaps act on the basis of that judgment. But one will typically not form the same judgment on the sole basis of visually imagining that $o$ is $F^{13}$

Accordingly, a plausible third condition is this: imagery lacks assertoric force. When one images the redwood tree, there is no character or content of this mental episode that says, as it were, "there is a redwood tree, here-and-now". Perception does just this: a perceptual experience as of a redwood tree enjoys assertoric force. It says to the perceiver, "there is a redwood tree, here-and-now". And an hallucination as of a redwood tree, just like a perception thereof, says to one that "there is a redwood tree, here-and-now". This explains the contrasts mentioned just above. Absent relevant self-knowledge (that one is hallucinating), one may form judgments, beliefs, and intentions to act in immediate response to hallucination (those resultant states all having contents partially constituted by there being a redwood tree here-and-now), and one may well enjoy defeasible justification for

\footnotetext{
${ }^{13}$ Some argue, however, that hallucination is a kind of imagery. See Nanay (forthcoming).
} 
beliefs formed on that basis. Imagery, lacking assertoric force, differs with respect to these cognitivebehavioural and epistemic features. ${ }^{14,15}$

This difference in assertoric force might be grounded in an important difference in phenomenology. Dominic Lopes marks this difference with a concept borrowed from Sartre: visual imagery is subject to the "illusion of immanence".

$[\mathrm{W}]$ hen we visualize a scene...we introspect the properties of some mental object, the vehicle of the visualizing, where those properties match those of the imagined scene. In visualizing it is as if we introspect mental objects that have the visual properties of objects in the non-mental world. Thus when I visualize a chartreuse gorilla it seems that I introspect a mental object that is the vehicle of my visualizing and that is chartreuse and gorilla-like in appearance. Properties visualized seem to be "stuck on" the vehicle of experience. (Lopes 2003: 209).

One also experiences those properties as being properties of the object imaged. But the important difference is that visual perceptual experiences do not suffer this illusion: one doesn't take the perceived properties to be properties of some mental representation but instead to be properties of the external object of perceptual representation. ${ }^{16}$ Perceptual experiences are then, by contrast, transparent. ${ }^{17}$ The illusion of immanence — this lack of transparency-blocks, or at least substantially diminishes, any potential assertoric force of imagery. Images are more like pictures than perceptions in this regard: one takes, in part, the imagined properties to be properties of one's own mental image (the representational vehicle), just as one can be aware of both a picture's features and the features of what's pictured. Accordingly, imagery experiences, like pictures, are less apt to assert how things

\footnotetext{
${ }^{14}$ More carefully, if imagery has these features, it seems not to have them in the same way. One might form an image and, on that basis, form justified beliefs about possibilities and plan action (for example about the possibility of fitting the piano through the front door of the house). But here the resultant beliefs and other mental states are qualified in an important way, with a modal operator, rather than being about here-and-now actualities. And this can be acknowledged while maintaining the proposed distinction between imagery, on the one hand, and both veridical perception and hallucination/illusion, on the other.

${ }^{15}$ For a recent collection of papers on assertoric force and content, see Brown and Cappelen (2011). For recent discussion of assertoric force and perceptual experience, see Matthen (2005), and Siegel and Silins (2015). For additional defence of an assertoric force condition for imagery, see Stokes and Biggs (2014).

16 To attribute the properties represented by a perceptual experience to the experience itself is a famous theoretical mistake, dubbed the phenomenological fallacy by U.T. Place (1956)

${ }^{17}$ Harman (1990).
} 
are here-and-now in one's environment. But perceptual transparency does just that, enabling an assertion about the perceiver's here-and-now.

Pairing all of this with the first two identified features of imagery yields the following: A visual imagery experience is a quasi-perceptual mental state or process that (i) resembles the representational content and phenomenology of a visual perceptual experience; (ii) is typically had in the absence of the appropriate external cause; and (iii) lacks assertoric force.

This is only a working definition, but it nonetheless suffices to distinguish imagery from other relevant phenomena: from belief, perception, and propositional imagination.

Again, only conditions $i$ and ii are needed for the analysis that follows. Some will deny the assertoric force condition ${ }^{18}$ and opt for some alternative third condition. Other candidates in traditional and contemporary literature include the following (all by contrast with perception). Mental images causally depend upon previous sensory information or perceptual experience. Images are often under immediate voluntary control. Images are less vivid than perceptual experiences. Readers are welcome to supplement the characterization of imagery in terms of $i$ and ii, as their independent theoretical commitments dictate.

\section{Empirical measures of imagery}

A general method for experimental study of imagery involves identifying relations in behavioural performance on both perceptual tasks and imagery tasks in the same modality. Two classic studies in this category involved mental rotation tasks. In Shepard and Metzler (1971), subjects are presented with two images (see Figure 1). The right hand image is either identical but rotated, or a mirror image (so backwards). Similarly, in Cooper and Shepard (1973) subjects were

\footnotetext{
18 See Briscoe (2011); Nanay (2010; 2015; forthcoming).
} 
presented with two letters. The right hand letter was either the same letter but rotated, or a mirror image of the letter (so backwards). In both sets of studies, subjects have to determine whether the right hand image is a match or a mirror image, relative to the image on the left. Researchers hypothesize that this will encourage formation of a visual image, which is then rotated and compared. The results support this hypothesis; in both studies, the response times closely co-vary with the rotational differences between the two images. A second type of paradigm involves mental scanning. In Kosslyn et al. (1978), subjects are asked to memorize a visually presented map. Subjects are then asked to visualize the map (with the map absent from sight) and scan from one identifiable location to another and report when they "see" the second location. Here again the results are instructive: subjects' response times are a linear function of the distance between the locations as found on the map.

\section{[insert figure 1 here]}

A third broad category of experimental paradigm involves interference between concurrent perceptual and imagery tasks. Perhaps the most famous example is the Perky Effect (Perky 1910). Here subjects facing a screen are asked both to visually fixate on a point and to form a visual image of a familiar object (for example, a banana). While subjects are performing the imagery task, an image of the to-be-imagined object type (a banana) is slowly illuminated on that screen, just above the threshold for visual recognition. What researchers found is that, once the image was illuminated, subjects were unaware that they were in fact visually perceiving rather than imaging the familiar object. ${ }^{19}$ It therefore appears that perceptual performance interferes with imagery performance.

\footnotetext{
19 This experiment is controversial. See Segal (1971, 1972); Hopkins (2012); Reeves and Craver-Lemley (2012). This controversy notwithstanding, no appeal is made to what lessons should be drawn from Perky's original studies. It is simply an early example of a perception-imagery interference study.
} 
More recent studies find interference going in the other direction as well: forming images can hinder concurrent performance of a perceptual task.

A recent series of experiments employs this broad interference method as a way of testing for imagery in language processing. The standard paradigm is to give subjects a visual spatial task (for instance, identifying objects presented in different regions of a presentation screen) while concurrently presenting, typically audibly, a sentence. Generally, the studies suggest that subjects are forming images in response to the sentences presented, since they suffer interference in the visual task. What is interesting, and in particular for an interest in imagery and fiction, is that different manipulations to the presented sentences-literal vs figurative, motion verbs in the direction of the concurrent perceptual task vs not- modulate (or eliminate) the interference effect in significant ways. The study most relevant here is Bergen et al. (2007). Two experimental structures are discussed now, and then two more in IV below.

The first experiment involved verbs typically associated with upward or downward motion. For example:

The mule climbed. [Upward motion] The chair toppled. [Downward motion]

Subjects were placed before a computer screen. They were asked to fixate on a cross at the centre of the screen for $1000 \mathrm{msec}$. This was followed by a verbalized sentence like one of those above (subjects wore headphones). Then a $200 \mathrm{msec}$ inter-stimulus pause. Then a circle or square would appear (always at the same distance from the central fixation cross), for $200 \mathrm{msec}$, either in the top, bottom, left, or right part of the screen. The task was to report whether the presented object was a circle or a square (by pressing one of two corresponding keys on the computer keyboard). (It is crucial to note that subjects are ${ }^{*}$ not* asked to form visual images in response to the audibly presented sentences.) The prediction was that interference with the visual task would co-vary with 
the motion of the presented verb. For instance, a trial with a sentence involving an upward verb like 'climb' would interfere with identification of an object when it was located in the upper part of the screen (but no such interference would occur in a trial with an upward motion verb and an object presented in the lower part of the screen). The results support this prediction. Response times varied in precisely this way: subjects took longer to perform when the motion of the presented verb aligned with the location of the object to be visually identified. This suggests that subjects are forming visual images in a way that accords to the motion or spatial aspects of the linguistic stimuli, which accordingly interferes with a visual perceptual task when and only when that task concerns the region of space corresponding to the motion of the verb.

Experiment 2 was structured the same, but with manipulation of nouns instead of verbs. (Verbs were held constant with respect to their upwards or downwards association.) Sentences involved nouns that are typically associated as being "upward" or "downward". For example:

The cellar flooded. (noun down) The ceiling cracked. (noun up)

Here the results suggest the same kind of interference. For instance, upward oriented nouns like 'ceiling' significantly interfered with the perceptual identification task when and only when the target object was located in the upper part of the screen. And again, there is a robust empirical precedent for taking these kinds of interference effects to indicate visual imagery.

An interpretive question follows: Is the interference (and thus the mental imagery) a result of the whole-level sentential description? Or is this just an effect of associations with single lexical items (such as an upward motion verb)? Bergen et al. favour the former answer, for reasons that will be considered in IV. 
For now, these findings can be connected with the topic to be analyzed in the section that follows - imagery and its role in imagination generally. One might be tempted by this line of thought. If sentences as simple as those listed above (from Experiments 1 and 2 of Bergen et al. 2007) evoke imagery, then we have behavioural evidence that fictional narratives generally evoke imagery. And perhaps one will be tempted further to claim that formation of mental images is somehow essential for the imagining that readers exercise when reading fictions. This is a tempting line of thought, but it will now be argued that it fails. Instead we find that because appropriate engagement with fictional narratives does not require (in many cases, cannot involve) visual or other perceptual imagery, it follows that imagination does not require imagery. And this anti-essentialism is well corroborated by the additional experiments in the Bergen et al. studies.

\section{Fiction and (anti-) imagery essentialism}

\section{IV.1. Kind's essentialism and an initial challenge}

Against the dominant trend to emphasize propositional imagination at the cost of any emphasis on imagery, Kind argues that images are essential to instances of imagining. Her claim is that mental images are necessary (but not sufficient) to make a mental exercise an exercise of the imagination. Kind motivates this claim abductively, framing her argument around the following three desiderata for a theory of imagining.

(i) Directedness: In imagining $\mathrm{X}$, I direct my imagining at something.

(ii) Activity: To imagine $\mathrm{X}$ is to do something.

(iii) Phenomenology: Imagining $\mathrm{X}$ has a qualitative character.

Directedness (i) captures the idea that imaginative states are intentional or representational. Accordingly, one's imagining represents—is directed at—some event, object, or feature, actual or not. Activity (ii) is understood by contrast: to imagine is not to enjoy a passive mental state (as some have characterized sensory states, for example). It is instead to act or exercise one's mind in some 
way. The phenomenology desideratum (iii) maintains, in the now familiar idiom, that there is something that it's like to imagine. Kind's argument is that because an imagery-based account of the imagination best meets these three desiderata, it is our best theory of the imagination.

As one would predict, the way to test or challenge Kind's essentialist claim is to challenge the necessity of imagery to an exercise of the imagination by invoking plausible counterexamples. Kind anticipates this rejoinder, and so spends part of her analysis defending her position against what appear to be difficult cases for an imagery-based account. Here are two cases that she explicitly considers. Imagine:

(1) Bill Clinton had a secret desire to be a rock $\mathrm{n}$ roll star.

(2) Bill Clinton doing budget calculations in his head.

On the face of it, to successfully imagine (1) or (2), one does not need to form a mental image (in whatever sensory modality). Kind defends her essentialism by marking a distinction: cases like (1) and (2) are ones for which a variety of possible images are adequate, but nonetheless some mental image or other is necessary. To evaluate these cases and imagery essentialism as defended, one needs to ask about the logical force in question: in what sense is some image necessary to imagine cases like (1) or (2)? It certainly isn't the case that upon presentation of these sentences one must, as a psychological or conceptual fact, token a mental image. So it must be that the logical force concerns some important role performed by the image, in terms of making the imagining of which it is a part, correct or appropriate or adequate. The role in question concerns determination of content. The imagery essentialist claims that images play a necessary role in determining the content of one's imagining. And here essentialism can vary in strength. Dominic Gregory distinguishes two possibilities:

Pure imagery essentialism: Every possible imagining is such that, first, it features some accompanying sensory mental images and, second, its content is determined entirely by the contents of its accompanying mental images. 
Impure imagery essentialism: Every possible imagining is such that, first, it features some accompanying sensory mental images and, second, its content is at least partly determined by the contents of its accompanying mental images.

(Gregory 2016: 104)

If Kind were committed to pure imagery essentialism, then her view would be easily challenged by cases as simple as (1) and (2). But she only commits to impure imagery essentialism, and she does this by marking a distinction between the essentialist thesis and an individuative thesis.

The essentialist thesis ET, recall, claims that mental images play an essential role in the imagination (they are necessary but insufficient). The individuative thesis IT, as Kind defines it, claims that images individuate imaginings. Kind then argues that ET and IT are logically independent. Commitment to ET does not entail commitment to IT, and she is only committed to ET. And because the alleged counterexamples to ET instead challenge only IT, ET survives. The reasoning is sound as far as it goes. One easy way to see the logical independence of the two claims is to consider examples where something other than an image does the work of individuating the imagining. Thus, one can token the same image type on two different occasions, but while imagining two distinct contents. One might form an image like Figure 2, first to imagine a man walking laboriously up a steep hill, and second to imagine a man casually moonwalking in the style of Michael Jackson down a steep hill. Same image, different imagining.

[Insert Figure 2 here]

Conversely, one can form distinct images to imagine the same content. To imagine that there is a cat on a mat, one can form all manner of visual images of cats on mats, ranging from the realistic to the cartoonish. Kind infers from these cases that, contrary to IT, something other than the image can do the work of individuating an imagining. Put in terms of content, something other than (or in 
addition to) the image partly determines the content of one's imagining. Thus IT is false, but this leaves logical space for ET.

Kind's denial of commitment to IT entails that, for some imaginings, there are non-imagistic determinants of content which, in turn, individuate imaginings. It is in this sense that Kind commits only to impure imagery essentialism. This forces a question: if not the role of entirely determining the content of an imagining, what necessary role do images play? Kind's answer is that images play the capturing role.

Suppose I were trying to paint a portrait of Bill Clinton. As we have seen, in such a case, the paint I use would not itself be the object of my activity. Rather, the role the paint plays would be to capture the object of my painting, in this case, Bill Clinton. Similarly, if I were trying to imagine Bill Clinton, the image I use would not itself be the object of my activity. But the role that the image plays is to capture the object of my imagining, in this case, Bill Clinton (Kind 2001: 108).

An image serves the role of capturing — getting a referential grip on, thus being directed at—an object, where here Kind understands 'object' liberally (for example, objects could perhaps include singular events). Granting the distinction between IT and ET and the lessons learned there, Kind urges that a variety of images, for any one imaginative project or imagining-type, could serve the capturing role. So the essential role played by images is one that connects with the content of imagining, where the image (which could vary from person to person or project to project) captures the object or event at which the imagining is directed. And that object is at least partly constitutive of the content of one's imaginative state. Adjusting the dialectic accordingly, challenges to impure imagery essentialism must be cases where images could not or need not serve the capturing role in determining the content of an imaginative state.

Here are some possible counterexamples, in addition to the two already mentioned. Imagine:

(1) Bill Clinton had a secret desire to be a rock $\mathrm{n}$ roll star.

(2) Bill Clinton doing budget calculations in his head.

(3) Jones was from Chicago; Smith was from Queens. 
(4) Dr. Beck then realized that she would have to inform the patient that his DNA matched neither of his parents.

(5) Elves live forever.

(6) The invisible time travel machine was now complete.

(7) The man fell into a despair as deep as a black hole.

These examples plausibly divide into three types of case:

(c1) Cases for which there seems to be no relevant image.

(c2) Cases for which an image seems unnecessary.

(c3) Cases for which multiple distinct images are sufficient.

We now have an account of the logical force of the quantifiers here: they all connect with the need for an image in performing the capturing role. Thus (c1) is to be read as: Cases for which there seems to be no relevant image to serve the capturing role. Likewise for (c2) and (c3). Cases that fall under (c3) are safe for impure imagery essentialism: they are neutral with respect to ET. Kind defends (1) and (2) as instances of (c3). For example, for (2), one might form an image of Bill Clinton with a scrunched up face, or staring out the window, or taking a shower (Kind jokes that for some people this is where their best thinking gets done). What is presumably needed, on Kind's account, is some image of Clinton in order to capture him as the object of one's imagining. One might further defend (3) and (4) as cases of type (c3), but a bit more consideration should at least raise suspicion.

Cases that fall under either (c1) or (c2) are clear challenges for impure imagery essentialism. Instances of either case type entail that an image is not needed to serve the partial contentdetermining, capturing role. The question regarding candidate cases of type (c2) is this: is an image needed to capture an object (assuming that there is an object)? It is less than clear how one should answer this question for (3) and (4). Here of course one could form mental images, say of a pair of men or women and of Chicago and of Queens. And one could form a generic image of a doctor and perhaps a chart on a clipboard. And one can further think of a variety of alternative images for each case. But this is insufficient to motivate the claim that there must be an image to capture the objects or events constitutive of the contents of the relevant imaginings. 
And things are more challenging once we move to cases (5)-(7). These are plausible instances of type (c1), where here the questions are: is there an object or event of one's imagining and, if there is, is it image-able? Case (5) is a good candidate, when one imagines it, for a de dicto imagining. Interpreted as containing an implicit universal quantifier, there is no individual or even set of particulars to be captured by any image. And it further involves an abstract concept of infinite time. So one might worry here that there is no object to be captured by an image (before one worries about whether there is an appropriate image).

With (6) and (7), perhaps there is some clear object to be captured (a machine and an emotional event, respectively). But here it is difficult to identify an appropriate image to perform the role of capturing. What image would capture an invisible time travel machine? What image would capture a temporally extended emotional event metaphorically described in terms of an invisible event in outer space? The point here is not just that cases like these fail to trigger an image involuntarily (as some of cases (1) through (5) may do), but that there is no appropriate image for one to form voluntarily, even with considerable effort. ${ }^{20}$

What counts as a "proper" or "appropriate" imagining given some targeted object (or a fictional prescription) is an important and largely unanswered question in the philosophy of imagination. But in this context the question is more tractable. It is: what counts as an appropriate image for capturing (in Kind's sense) the object or event of one's imagining? The answer is not different in structure from the one given for the case of language. If I want to describe an event where a man crosses the street, there may be a set of appropriate descriptions and some vagueness in demarcating that set. But there is also a very large number of descriptions that would simply fail to capture, get any referential grip on, that event. Shy of effecting some dramatic change in one's linguistic community, none of the following would be appropriate: 'The cat is on the mat.', 'We are

${ }^{20}$ Thanks to an anonymous referee for emphasizing this point. 
out of toothpaste.', ' $2+2=4$ '. The same is true for imagination, including imagery. There may be a large set of appropriate images for capturing an individual object or event, but there are many that are just not appropriate. Forming an image of a red wheel barrow does not capture Clinton, whatever it does capture. And forming an image of a visible, say, DeLorean does not capture an invisible time machine. In neither case is the image used appropriate for the targeted object.

Some of these cases, and more sophisticated analysis thereof, look challenging for any imagery essentialism, including Kind's impure essentialism. But there is a great deal of space for debate. The challenge can be sharpened by moving away from stand-alone, philosopher's fictions, to larger scale fictional narratives. When coupled with some additional empirical data, the challenge to the abductive argument for imagery essentialism looks fatal.

\section{IV.2 A challenge to essentialism from fiction and abstract language}

The best squadron in each wing won a yellow pennant on a pole that was utterly worthless. The best squadron on the base won a red pennant on a longer pole that was worth even less, since the pole was heavier and was that much more of a nuisance to lug around all week until some other squadron won it the following Sunday. To Yossarian, the idea of pennants as prizes was absurd. No money went with them, no class privileges. Like Olympic medals and tennis trophies, all they signified was that the owner had done something of no benefit to anyone more capably than everyone else. J. Heller, Catch-22

There were one quadrillion nations in the Universe, but the nation Dwayne Hoover and Kilgore Trout belonged to was the only one with a national anthem which was gibberish sprinkled with question marks.

It was the law of their nation, a law no other nation on the planet had about its flag, which said this: "The flag shall not be dipped to any person or thing.

K. Vonnegut, Breakfast of Champions

I woke up as the sun was reddening; and that was the one distinct time in my life, the strangest moment of all, when I didn't know who I was - I was far away from home, haunted and tired with travel, in a cheap hotel room I'd never seen, hearing the hiss of steam outside, and the creak of the old wood of the hotel, and footsteps upstairs, and all the sad sounds, and I looked at the cracked high ceiling and really didn't know who I 
was for about fifteen strange seconds. I wasn't scared; I was just somebody else, some stranger, and my whole life was a haunted life, the life of a ghost.

J. Kerouac, On the Road

Recall that impure imagery essentialism requires that for each fictional $P$, one must form some sensory, mental image to capture the object of one's imagining (and thereby partly determine the content of one's imagining that $P$ ). Therefore, counterexamples from fiction only need to involve one fictional $P$ for which there is no relevant image, or for which there is no image needed to capture constitutive parts of $P$. It is here that the richness of fictional narrative is especially instructive.

In each of the above passages, there are multiple candidates for cases of types (c1) and (c2): fictional propositions that comprise no clear object to be captured or an object that is not imageable, and fictional propositions where there is no clear reason to think that an image is needed to capture an object. Some examples: One might form an image of Yossarian to imagine the contents underlined in the passage from Catch-22. But this would be a more appropriate image for other parts of the narrative. And one could imagine Yossarian's thoughts about pennants, prizes, money, and class privileges without an image of Yossarian, and indeed without an image of anything. So this is a plausible instance of (c2). Much of the passage from Breakfast of Champions lacks an object to be captured. Of course one could image the two named characters, but this would not adequately capture objects constitutive of propositions concerning a quadrillion nations, the Universe, national anthems sprinkled with gibberish, or laws about flag-dipping. So these are plausible instances of (c1), where there are no objects or events to be captured by an image. Finally, there are parts of the passage from On the Road that clearly evoke imagery and would require it for appropriate imagining. But other propositions to be imagined (namely, those expressed by the sentences underlined in part) are propositions for which, if there is some object or event—being far away from home, being 
uncertain about one's character or identity, living the haunted life of a ghost—are not ones for which there is an appropriate image. And so these too are plausible instances of (c1).

One could resist the interpretation given of any of these fictional propositions. And perhaps when we isolate each fictional proposition, the interpretation given will not be structurally different from those given of (3)-(7) above. But this misses the value of turning away from isolated sentences or propositions and instead to fictional narrative. It misses the contrasting richness of fictional narrative. One way to put this is Walton's: fictions prescribe contents for one to imagine (Walton 1990). And indeed they prescribe lots and lots of things for us to imagine, one prescribed content after another. Insofar as a competent reader complies to some substantial degree with these prescriptions, she will imagine many, many contents. And it is implausible that for each of these imagined propositions, one must form a mental image. Consideration of these passages from actual fictions should make this undeniable. And, again, the challenge to essentialism only requires one case (of type (c1) or (c2)). Here we have several strong candidates, and could adduce countless more by grabbing almost any novel or play or collection of poems off the bookshelf.

One clear feature of some parts of these passages is that they involve metaphorical or abstract language. And these are cases that plausibly do not require any imagery for their imagining. Additional empirical evidence corroborates this interpretation. Recall that experiments 1 and 2 from the Bergen et al. studies showed interference effects for sentences containing up/down motion verbs and up/down associated nouns. All of the sentences used in those two experiments described literal movement or location. The second two experimental paradigms in the study used figurative language. Both of them were otherwise structured exactly like experiments 1 and 2, described in III above.

Experiment 3 used as (auditory) stimuli, sentences that describe metaphorical motion. As a pair of contrasts: 
The drainpipe climbs up the back wall of the house. (literal motion)

Oil prices climbed above $\$ 51$ per barrel. (metaphorical motion)

In the same kinds of task as the earlier experiments, subjects showed interference with the visual perceptual task only when presented with sentences describing literal motion, but no interference for metaphorical motion sentences.

Experiment 4 employed abstract quantity verbs. Here are two examples:

The figures doubled. [Abstract Up]

The percentage decreased. [Abstract Down]

As an additional complication, here the researchers note that in a norming study regarding associations with the verbs used, verbs like 'double' and 'decrease' do in fact exhibit up and down associations, respectively. This strengthens the value of this experiment in the following way. Since these verbs are associated with up-ness and down-ness, if it is just the mere term (and its lexical association) that causes imagery in these studies, then interference effects should occur for these kinds of sentences, and in spite of the fact that they are here used abstractly or figuratively. But indeed what the results show is that subjects suffer no interference with visual tasks in response to sentences like these.

Since interference effects show only in response to sentences describing literal motion or spatial location, Bergen et al. conclude that "it is not lexical priming that yields the interference but rather the performance of mental imagery corresponding to the meaning of an utterance" (2007: 758-9). Now of course these data do not suffice to conclude that no figurative language evokes imagery. For example, it may be that imagery of that kind generally occurs on a timescale different from imagery about literal sentences, and these experiments are simply insensitive to that timescale. 
That possible confound notwithstanding, these data do converge with, and offer additional abductive

leverage for, the case against essentialism. And the leverage consists in a novel explanation of the examples employed there. When we read fictions, we take in sentence after sentence and imagine content after content. These data suggest that either we do not always form mental images in reply to figurative sentences, or we don't do so rapidly enough, before we are on to the next content to be imagined. $^{21}$

\section{$V$. Rejoinders from essentialism and conclusion}

One possible rejoinder for the essentialist is to grant that for these fictional propositions the reader is not forming mental images, but deny that the reader is forming any imaginative state in response. And if one is not imagining in reply to the relevant parts of the narratives, then the lack of imagery is no challenge to the essentialist thesis.

There is something to this rejoinder: it certainly is not the case, nor is it a plausible condition on proper uptake of fiction, that we imagine every content given by a fiction upon a single reading (and this is true even if we consider only those propositions explicitly expressed by sentences in the text). But this admission will not save essentialism. For even if there are some sentences that a reader reads, but does not then form an accordant imagining, there are many others where she does just this (and this will vary from reader to reader). The challenge to essentialism only requires that some of these imaginings do not comprise an image.

\footnotetext{
21 A challenge for essentialism so far unmentioned comes from individual differences. Anecdotally, some claim not to form visual (or other sensory) images, in response to fictions or otherwise. And there is some literature on individual differences in imagery (See Poltrock and Brown 1984; Borst and Kosslyn 2010; Kozhevnikov and Blazhenkova 2012). In the strongest cases, these differences allegedly consist in some individuals—subjects with congenital aphantasia— who simply cannot form sensory images (Zeman et al. 2015). Imagery essentialism may then be faced with a dilemma: either these individuals simply do not have the capacity to imagine (because imagining requires imagery) or they imagine in non-imagistic ways. The first horn maintains essentialism but is implausible behaviourally (some of these subjects can still engage hypothetical reasoning, consider counteractual possibilities, read fictions); the second horn undermines essentialism. For the sake of charity, this challenge has been set to one side. And the only assumption needed for the positive analyses given here is that some substantial percentage of readers do image in response to fictions.
} 
One way to make this clear is to invoke Kind's second desideratum for a theory of imagination, which says that imagining is an active mental exercise. There are various reasons to think that our engagement with fiction is active. First, readers respond with affect. In the above examples, perhaps one responds with amusement to Yossarian's views on prizes, or to the universe of Kilgore Trout; and perhaps with melancholy and compassion for Sal's existential musings in $O n$ the Road. Second, readers become cognitively engaged, in rich and various ways, with what is read. Readers draw inferences, make comparisons, wonder or become curious about characters and events. These respective emotional and cognitive effects causally (or constitutively) depend upon appropriate mental states. Although it is surely true that some fictional contents are simply read and understood passively, more activity is required in instances where readers experience affect and rich cognitive engagement. This implies that, for those fictional propositions, readers are not merely understanding, entertaining, or supposing. These processes are insufficiently active to generate those affective and cognitive responses. One might then suppose that the relevant mental state is belief (or, illusory belief); one forms many beliefs about these propositions and accordingly experiences affect and becomes cognitively engaged. This, however, is a dead end, and for familiar reasons. We do form beliefs about things described in fictions, but this is not what we are doing most of the time. ${ }^{22}$ The remaining candidate mental process is imagining. We form imaginings in response to many of the propositions expressed by a fictional narrative. And these imaginings, as it has been well-defended in many places, may cause both emotional affect (or at least phenomenology very much like genuine emotional affect) and rich cognitive engagement. ${ }^{23}$ The claim defended here,

\footnotetext{
22 See Currie (1990); Walton (1990); Gendler (2000, 2003).

23 On imagination and affect, see Walton (1978), Currie (1997), Currie and Ravenscroft (2002), Gaut (2003). On imagination and cognition, see Currie (1990); Gendler (2003); Nichols and Stich (2000, 2003); and for a recent collection of papers, Nichols (2006).
} 
again, is that some of these imaginings will not involve any imagery, while still being about the contents prescribed by the narrative.

The second possible rejoinder for the essentialist is to appeal again to the claim that the imagery-based account is abductively superior. Recall that Kind's position is that imagery essentialism is not motivated as a conceptual matter, but that such an account best explains various features of the imagination. In drawing the distinction between IT and ET, Kind maintains that images do not solely individuate imaginings, but images do capture the object of one's imagining. The relevant abductive claim is that images best serve the capturing role.

A counter to this line of argument is that some kind of linguistic, or semantic, or otherwise image-less imagining could serve the capturing role. Recall examples such as these, where the reader is asked to imagine:

(2) Bill Clinton doing budget calculations in his head.

(5) Elves live forever.

(7) The man fell into a despair as deep as a black hole.

Now perhaps one can form an image to capture relevant objects of imagining for each of these propositions. But one could alternatively form a propositional imagining, or perhaps an imaginative state in the language of thought, and adequately capture the relevant objects of imagining. So why claim that an image is necessary for propositions like these?

The move for an essentialist is to appeal to Kind's third desideratum for a theory of imagination:

(iii) Phenomenology: Imagining $\mathrm{X}$ has a qualitative character

So, Kind will claim, it is not that a non-imagistic explanation fails conceptually. It is rather that an imagery account (and thus images as the relevant vehicles for capturing the objects of one's imagining) best explains a fact about imagination: namely, it involves a phenomenology. 
There is something that it's like to imagine.

But here one can ask about the nature of the phenomenology needed. That is, suppose for argument's sake that (iii) is a criterion for a successful theory of imagination. Clearly one kind of possible phenomenology is sensory-perceptual. Perhaps for (2) one forms a vivid, visual image of Bill Clinton and his facial features, where what it's like to have this imagery experience is subjectively similar to what it's like to visually perceive Bill Clinton. But this is not the only possible kind of phenomenology. Emotional states enjoy phenomenology. For example, perhaps one empathizes with the character described in (7). This is all the more true if (7) is embedded in a longer fiction about this character and his causes for depression. If one empathizes with Sal, as he describes his momentary identity crisis in $O n$ the Road, this empathetic experience enjoys a phenomenology. Or perhaps one wonders or puzzles or otherwise cognitively engages these kinds of propositions. One might wonder about the cause of the despair in (7) absent some further back story. Here again consideration of actual fictions proves more instructive. One surely wonders about the national anthem and flag-dipping in the world of Kilgore Trout, when reading the Vonnegut passage. So although some philosophers deny such a thing ${ }^{24}$, perhaps one sometimes enjoys cognitive phenomenology when imagining.

The point here is that these are two defensible candidates for the phenomenology that comes with active, directed imagination, and that could occur without the presence of a mental image. Combined with analysis of actual fictional narratives and the empirical data discussed, all of this shifts the abductive weight in favour of the anti-essentialist. The final possible rejoinder for the essentialist is to insist that the phenomenology must be sensory-perceptual, and thus an image is needed as part of the putatively best explanation. But this is to secure imagery essentialism only by begging the central question of the debate.

24 See Dennett (1988). For a recent volume of papers, see Bayne and Montague (2012). 


\section{Conclusion}

The motivation for this paper was to start to fill a particular gap in theorizing about fiction and imagination - to offer some critical analysis of imagery and its role in the appreciation of fiction. The prescription is that we gain better insight by considering genuine fictional narratives (rather than isolated fictional sentences created by philosophers) and how imagery is and is not evoked by those narratives.

Critically, the richness of our experience with fictional narratives reveals the shortcomings of imagery essentialism. We clearly do form mental images in response to the texts we read. But given the quantity and range of content given by fictional texts, it also seems that there are other nonimagistic activities of imagining, and ones that still amount to complex and proper appreciation of those texts. The empirical evidence suggests that some of this variety may depend upon differences in literal vs figurative, and spatial vs abstract, language.

The basis of this criticism also reveals, though, why the spirit of essentialism is deeply important. The discussion in section $\mathrm{V}$ focused on the affective and cognitive complexity of our engagement with fictions. Again the claim was that some of that complexity can be explained without appeal to imagery. We actively, mentally engage fictions, and with a variety of phenomenology, only some of which requires imagery. But some of this complexity does involve imagery, and so its theorizing is going to have to be imagery-based. And so this leaves a number of questions, all of them ripe for further analysis. When do we (need to) image in response to fiction, and when not? What kinds of literary or linguistic devices are especially likely to evoke imagery or, stronger, are ones for which proper appreciation requires imagery? Do we get richer engagement with a fiction if we do image? If so, how and to what effect-does imagery better promote rich affective response? more empathy to characters? more stimulating cognitive or intellectual or 
inferential engagement with the narrative? These are questions that a full theory of the imagination, and its role in our rich experiences with fiction, must address. And if we are going to make genuine theoretical attempts to answer such questions, then we must "put the image back in (our theories of) the imagination".

Earlier versions of this paper were given at the Imagination and Fiction Workshop, University of Konstanz, 2016, and The Annual Dubrovnik Conference on the Philosophy of Art, Dubrovnik, Croatia, 2017. Special thanks to all of the following for critical feedback: Greg Currie, David Davies, Jim Hamilton, Magdalena Balcerak Jackson, Julia Langkau, Hans Maes, Bence Nanay, Kathleen Stock, Neil van Leeuwen.

\section{Bibliography}

Bayne, T. and Montague, M., eds. 2012. Cognitive Phenomenology. Oxford: Oxford University Press, 2012.

Bergen, B., Lindsay, S., Matlockc, T., Narayanand, S. 2007. "Spatial and Linguistic Aspects of Visual Imagery in Sentence Comprehension." Cognitive Science 31: 733-64.

Borst, G. and Kosslyn, S. 2010. "Individual differences in spatial mental imagery.” The Quarterly Journal of Experimental Psychology 63(10): 2031- 2050.

Briscoe, R. 2011. "Mental Imagery and the Varieties of Amodal Perception.” Pacific Philosophical Quarterly 92 (2):153-173.

Brown, J. and Cappelen, H., eds. 2011. Assertion: New Philosophical Essays. Oxford: Oxford University Press.

Butterfill, S.A. \& Sinigaglia, C. 2014. "Intention and Motor Representation in Purposive Action." Philosophy and Phenomenological Research 88 (1):119-145.

Carruthers, P. and Smith, P.K., eds. 1996. Theories of Theories of Mind. Cambridge: Cambridge University Press.

Chalmers, D. 2002. "Does Conceivability Entail Possibility?” In Conceivability and Possibility, edited by Gendler, T. \& Hawthorne, J. Oxford: Oxford University Press. 145-200.

Cooper, L. and Shepard, R. 1973. “The time required to prepare for a rotated stimulus.” Memory \& Cognition 1: 246-50. 
Currie, G., 1990. The Nature of Fiction. Cambridge: Cambridge University Press. 1997. "The Paradox of Caring: Fiction and the Philosophy of Mind." In Emotion and the Arts,

Edited by Hjort, M. and Laver, S. Oxford: Oxford University Press.

Currie, G. and Ravenscroft, I. 2002. Recreative Minds. Oxford: Oxford University Press.

Davies, M. and Stone, T., eds. 1995a. Folk Psychology. Cambridge: Blackwell. 1995b. Mental Simulation. Cambridge: Blackwell.

Dennett, D. 1988. “Quining Qualia.” In Consciousness in Modern Science, Edited by Marcel, A. and Bisiach, E. Oxford: Oxford University Press.

Friend, S. 2008. "Imagining Fact and Fiction." In New W aves in Aesthetics, Edited by Stock, K. \& Thomsen-Jones, K. Palgrave-Macmillan. 150-169. 2012. "Fiction as a Genre." Proceedings of the Aristotelian Society 112: 179-209.

Gallese, V. 2000. “The inner sense of action. agency and motor representations.” Journal of Consciousness Studies 7(10), 23-40

Gendler, T. 2000. “The puzzle of imaginative resistance.” Journal of Philosophy 97(2): 55-81. 2003. "On the relation between pretense and belief." In Imagination, Philosophy, and the Arts, Edited by M. Kieran and D. Lopes. London: Routledge. 125-41.

Gregory, D. 2010. “Imagery, the Imagination and Experience.” Philosophical Quarterly 60 (241):735753.

2016. "Imagination and mental imagery." InThe Routledge Handbook of Philosophy of Imagination, Edited by Kind, A. London: Routledge.

Harman, G. 1990. “The intrinsic quality of experience.” Philosophical Perspectives 4: 31-52.

Hopkins, R. 2012. "What Perky did not show." Analysis 72 (3): 431-439.

Horgan, T. and Tienson, J. 2002. "The Intentionality of Phenomenology and the Phenomenology of Intentionality." In Philosophy of Mind: Classical and Contemporary Readings, Edited by Chalmers, D. Oxford: Oxford University Press.

James, W. 1890. Principles of Psychology. New York: Henry Holt and Company.

Jeannerod, M. 2001. "Neural simulation of action: A unifying mechanism for motor cognition.” NeuroImage 14(1), S103-S109.

1998. The Neural and Behavioural Organization of Goal-Directed Movements. Oxford: Oxford University Press.

Kind, A. 2001. "Putting the Image Back in Imagination." Philosophy and Phenomenological Research 62: 85-109.

Kosslyn, S., Reiser, B., Ball, T. 1978. "Visual images preserve metric spatial information: Evidence from studies of image scanning." J of Exp Pscyh: Human Perception and Performance 4(1): 47-60. 
Kozhevnikov, M. and Blazhenkova, O. 2012. "Individual Differences in Object Versus Spatial Imagery: From Neural Correlates to Real-World Applications.” In Multisensory Imagery, Edited by Lacey, S. and Lawson, R. Springer. 299-318.

Locke, J. 1690/2004. An Essay Concerning Human Understanding. R. Woolhouse (Ed.). London: Penguin.

Lopes, D. 2003. "Out of sight, out of mind." In Imagination, Philosophy, and the Arts, Edited by Kieran, M. and Lopes, D. London: Routledge.

Matthen, M. 2005. Seeing, Doing, and Knowing. Oxford: Oxford University Press.

Nanay, B. 2010. "Perception and imagination: amodal perception as mental imagery." Philosophical Studies 150 (2):239-254.

2015. "Perceptual Content and the Content of Mental Imagery." Philosopbical Studies 172 (7):1723-1736.

forthcoming. "Hallucination as mental imagery." Journal of Consciousness Studies. forthcoming B. "Perception and mental imagery in our engagement with art." In Art and Philosophy, Edited by Mag Uidhir, C. Oxford: Oxford University Press.

Nichols, S. ed. 1996. The Architecture of the Imagination. Oxford: Oxford University Press.

Nichols, S. and Stich, S. 2000. “A cognitive theory of pretense.” Cognition 74: 115-47. 2003. Mindreading. Oxford: Oxford University Press.

Pearson, J. \& Westbrook, F. 2015. "Phantom perception: voluntary and involuntary nonretinal vision." Trends in Cognitive Sciences 19 (5): 278-284.

Perky, C.W. 1910. “An Experimental Study of Imagination.” American Journal of Psychology (21) 42252.

Place, U.T. 1956. “Is Consciousness a Brain Process?” British Journal of Psychology 47: 44-50.

Poltrock, S. and Brown, P. 1984. "Individual Differences in visual imagery and spatial ability." Intelligence 8(2): 93-138.

Reeves, A. and Craver-Lemley C. 2012. "Unmasking the perky effect: spatial extent of image interference on visual acuity." Frontiers in Psychology 3: 1-7.

Rizzolatti, G. \& Sinigaglia, C. 2008. Mirrors in the Brain: How Our Minds Share Actions, Emotions. Oxford: Oxford University Press.

Shields, C. 2016. “Aristotle's Psychology.” The Stanford Encyclopedia of Philosophy. E. N. Zalta (Ed.), URL $=<$ http://plato.stanford.edu/archives/spr2016/entries/aristotle-psychology/ $>$.

Segal, S.J. 1971. "Processing of the Stimulus in Imagery and Perception." In Imagery: Current Cognitive Approaches, Edited by Segal, S.J. New York: Academic Press. 69-100 
1972. "Assimilation of a Stimulus in the Construction of an Image: The Perky

Effect Revisited.” In The Function \& Nature of Imagery, Edited by Sheehan, P. New York: Academic Press. 203-230.

Siegel, S. and Silins, N. 2015. "The Epistemology of Perception." In Oxford Handbook of Philosophy of Perception, Edited by Matthen, M. Oxford: Oxford University Press.

Stock, K. 2013. “Imagining and Fiction: Some Issues.” Philosophy Compass 8 (10):887-896.

Stokes, D. 2006. "Art and modal knowledge." In Knowing Art: Essays in Epistemology and Aesthetics, Edited by Lopes, D. and Kieran, M. Springer. 67-81.

Stokes, D. and Biggs, S. 2014. "The Dominance of the Visual." In Perception and its Modalities, Edited by Stokes, D., Matthen, M., and Biggs, S. New York: Oxford University Press. 350-78.

Shepard, R.N. \& Metzler, J. 1971. "Mental Rotation of Three-Dimensional Objects.” Science 171: 701-703.

Thomas, N. J.T., 2016. "Mental Imagery." The Stanford Encyclopedia of Philosophy. E. N. Zalta (Ed.), $\mathrm{URL}=<\mathrm{http}: / /$ plato.stanford.edu/archives/sum2016/entries/mental-imagery/>.

Thompson, E. 2008. "Representationalism and the Phenomenology of Mental Imagery." Synthese 160 (3):203--213.

Titchener, E.B. 1909. Lectures on the Experimental Psychology of the Thought-processes. New York: Macmillan.

Tye, M. 1991. The Imagery Debate. Cambridge, MA: MIT Press.

Van Leeuwen, N. 2013. “The Meanings of 'Imagine' Part I: Constructive Imagination.” Philosophy Compass 8 (3):220-230.

Walton, K. 1978. "Fearing Fictions." The Journal of Philosophy 75(1): 5-27. 1990. Mimesis as Make-Believe. Cambridge, MA: Harvard University Press.

Wundt, W. 1912. An introduction to psychology. London: George Allen

Yablo, S. 1993. "Is Conceivability a Guide to Possibility?” Philosophy and Phenomenological Research 53 (1):1-42.

Zeman, A., Dewar, M., Della Sala, S. 2015. "Lives without imagery - Congenital aphantasia." Cortex 73: 378-380.

Figure 1 

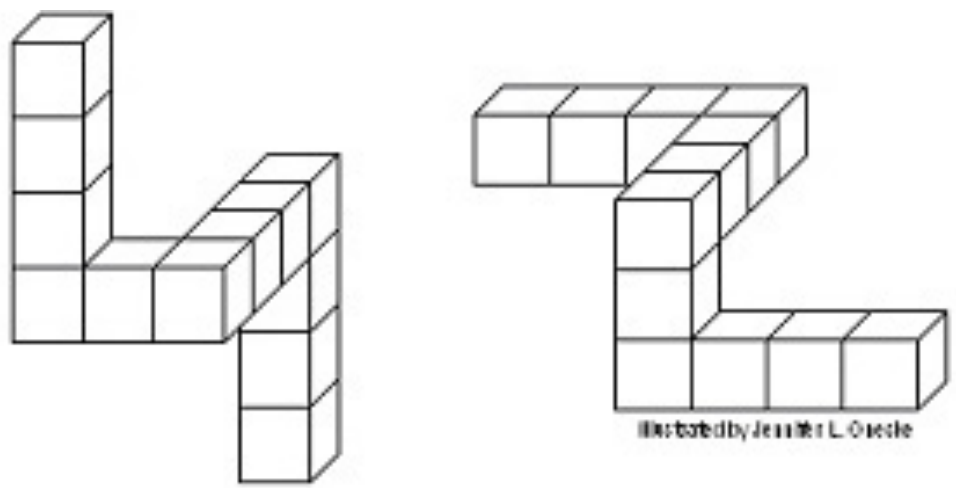

Figure 1: Based on Shepard \& Metzlar's 'Mental Rotation Task'

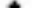

Source (public domain): https://en.wikipedia.org/wiki/File:MR_TMR.jpg

Figure 2

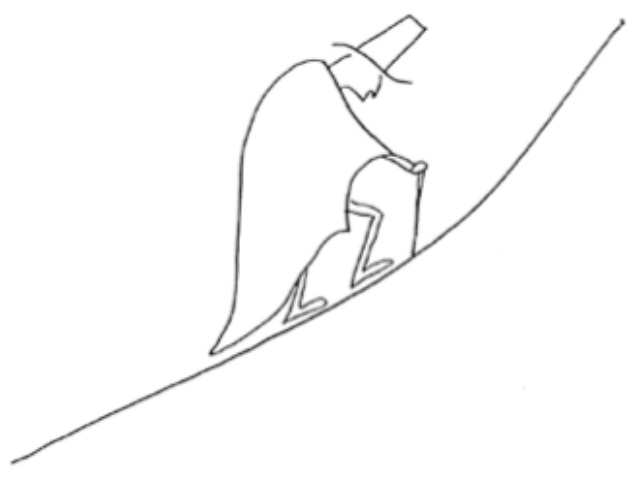

